\title{
EL MEDITERRÁNEO EN LA ESTRATEGIA DE SEGURIDAD NACIONAL 2013
}

\author{
Antonio Marquina ${ }^{1}$ \\ Universidad Complutense de Madrid (UCM) / Director de UNISCI
}

\begin{abstract}
Resumen:
Los planteamientos sobre el Mediterráneo que se realizan en la Estrategia de Seguridad Nacional 2013 son unos planteamientos en buena parte deficientes que no tienen en cuenta profundos cambios acontecidos en el Mediterráneo y su espacio de seguridad en los últimos años. El artículo expone las principales modificaciones que habría que introducir para hacer frente a las simplificaciones y omisiones que la Estrategia de Seguridad Nacional 2013 presenta con respecto al Mediterráneo.
\end{abstract}

Palabras clave: Estrategia de Seguridad Nacional, Mediterráneo, espacio de seguridad, Oriente Medio, Golfo Pérsico, amenazas y riesgos, Gibraltar, nuevos actores en el Mediterráneo.

Title in English: "The Mediterranean in the National Security Strategy 2013"

\begin{abstract}
:
The National Security Strategy 2013 considers the Mediterranean region as a priority area, but the approaches contained in the document are largely poor and don't take into account important changes that took place in recent years in the Mediterranean and its broader security space. The article explains first these changes and later describes the principal innovations that should be introduced to avoid the simplifications and omissions included in the Mediterranean section of the National Security Strategy 2013.
\end{abstract}

Keywords: National Security Strategy, Mediterranean, security space, Middle East, Persian Gulf, risks and threats, Gibraltar, new actors in the Mediterranean.

Copyright @ UNISCI, 2014.

Las opiniones expresadas en estos artículos son propias de sus autores, y no reflejan necesariamente la opinión de UNISCI. The views expressed in these articles are those of the authors, and do not necessarily reflect the views of UNISCI.

\footnotetext{
${ }^{1}$ Antonio Marquina Barrio is Chair of Security and Cooperation in International Relations, Director of the Department of Public International Law and International Studies of the Universidad Complutense de Madrid (UCM), Director of UNISCI and President of Foro Hispano-Argelino. His main research lines are security in Europe, the Mediterranean, Asia-Pacific, arms control and food security.

Address: Departamento de Estudios Internacionales, Facultad de Ciencias Políticas y Sociología, UCM, Campus de Somosaguas, 28223 Madrid, España.

E-mail: marioant@cps.ucm.es.

http://dx.doi.org/10.5209/rev_UNIS.2014.n35.4582]
} 


\section{Introducción}

El Mediterráneo, su seguridad y estabilidad ha constituido tradicionalmente una prioridad en la agenda de seguridad española. En este sentido es importante reseñar el impulso español para la plasmación de la conferencia Euro-Mediterránea de Barcelona y el diálogo mediterráneo de la OTAN en el período posterior a la guerra fría, con todo un conjunto de planteamientos posteriores más o menos afortunados, con la finalidad de mantener vivo el interés de la Unión Europea por la región mediterránea, de forma especial tras los atentados del 11 de septiembre de 2001 y la ocupación de Irak por los Estados Unidos. Estos acontecimientos produjeron un profundo extrañamiento entre el mundo árabe del Mediterráneo-Oriente Medio y el mundo occidental.

La diplomacia española, con mayor o menor acierto, trató, junto con otros socios europeos mediterráneos, de afrontar el reto y desarrollar un conjunto de iniciativas para hacer frente al creciente extrañamiento político, cultural, religioso, económico y de seguridad entre la Unión Europea y el Mediterráneo-Oriente Medio.

En este contexto interesa resaltar varios puntos. El 11 de marzo de 2003, días antes de empezar la ofensiva militar contra Iraq, la Comisión hizo pública una Comunicación al Consejo y al Parlamento sobre la política de vecindad con los vecinos del este y sur de Europa $^{2}$. Esta inclusión de los socios mediterráneos en la política de vecindad significaba privilegiar lo bilateral sobre lo multilateral en los procesos de cooperación, y también lo subregional. Era un cambio significativo, dadas las ineficiencias que ya presentaba el proceso de Barcelona. Posteriormente la Conferencia Euro-Mediterránea de Barcelona dio paso, en julio de 2008, a la Unión por el Mediterráneo, que pronto quedó en una situación de parálisis.

Por otra parte, el diálogo mediterráneo de la OTAN, fortalecido y reprogramado en diversas ocasiones, no llegó a cumplir los objetivos que se habían propuesto, las revoluciones árabes, iniciadas en Túnez en diciembre de 2010, se encargaron de poner de manifiesto la inadecuación de estas iniciativas y políticas diseñadas para hacer frente a los nuevos desafíos políticos, económicos, socio-culturales, religiosos y de seguridad, tal como se pretendió en la década de los noventa.

La Unión Europea trató de afrontar la nueva situación creada dándose cuenta del error cometido al minusvalorar la importancia del desarrollo político en sus iniciativas y políticas. El 8 de marzo de 2011, la Comisión propuso en una comunicación la creación de una asociación por la democracia y la prosperidad compartida con el sur del Mediterráneo que incluía una aproximación basada en el respeto a los valores universales e intereses compartidos, el principio de "más por más", con lo que la magnitud de los apoyos financieros, de acceso al mercado europeo y una mayor movilidad se hacía depender de los avances en la consolidación de las reformas democráticas de los socios mediterráneos. Dos meses después, el 24 de mayo, se adoptaba un nuevo documento titulado "una nueva respuesta antes un vecindario en cambio" que incluía seis pilares fundamentales ${ }^{3}$ a desarrollar. Ya en 2012 se estableció la hoja de ruta que había de guiar la puesta en práctica de la política de la Unión Europea con respecto a los socios del sur del Mediterráneo.

\footnotetext{
2 "Wider Europe-Neighbourhood: A New Framework for Relations with our Eastern and Southern Neighbours", COM(2003) 104 final, Bruselas (11 de marzo de 2003).

${ }^{3}$ Estos eran: Supporting progress towards 'deep democracy'; Intensifying political and security cooperation; Supporting sustainable economic and social development; Establishing Mobility Partnerships; Strengthening the Eastern Partnership and building a Partnership for Democracy and Shared Prosperity in the southern Mediterranean; Providing additional funding with clearer priorities.
} 
Pero sobre este continuo proceso de adaptación, en buena parte reactiva, sobrevolarán una serie de asunciones y presupuestos notablemente desfasados.

\section{La ampliación del tradicional espacio de seguridad mediterráneo: algunos planteamientos básicos previos a tener en cuenta}

En efecto, al mismo tiempo que se producían estos cambios reseñados en la aproximación de la Unión Europea al Mediterráneo, se producían de forma paralela otros cambios de importancia fundamental a los que la propia Unión Europea no prestó la atención que hubiera sido necesaria en función de las consecuencias que afectaban a los planteamientos y políticas que se estaban manteniendo.

En primer término la ampliación del espacio de seguridad mediterráneo ${ }^{4}$.

El espacio de seguridad mediterráneo, antes incluso de producirse las revoluciones árabes, no era ya el espacio definido por la Unión Europea en sus iniciativas, Conferencia euro-mediterránea de Barcelona y posteriormente Unión por el Mediterráneo (Véase Figura $1)$.

Figura 1. Espacio de seguridad de la conferencia euro-mediterránea de Barcelona.

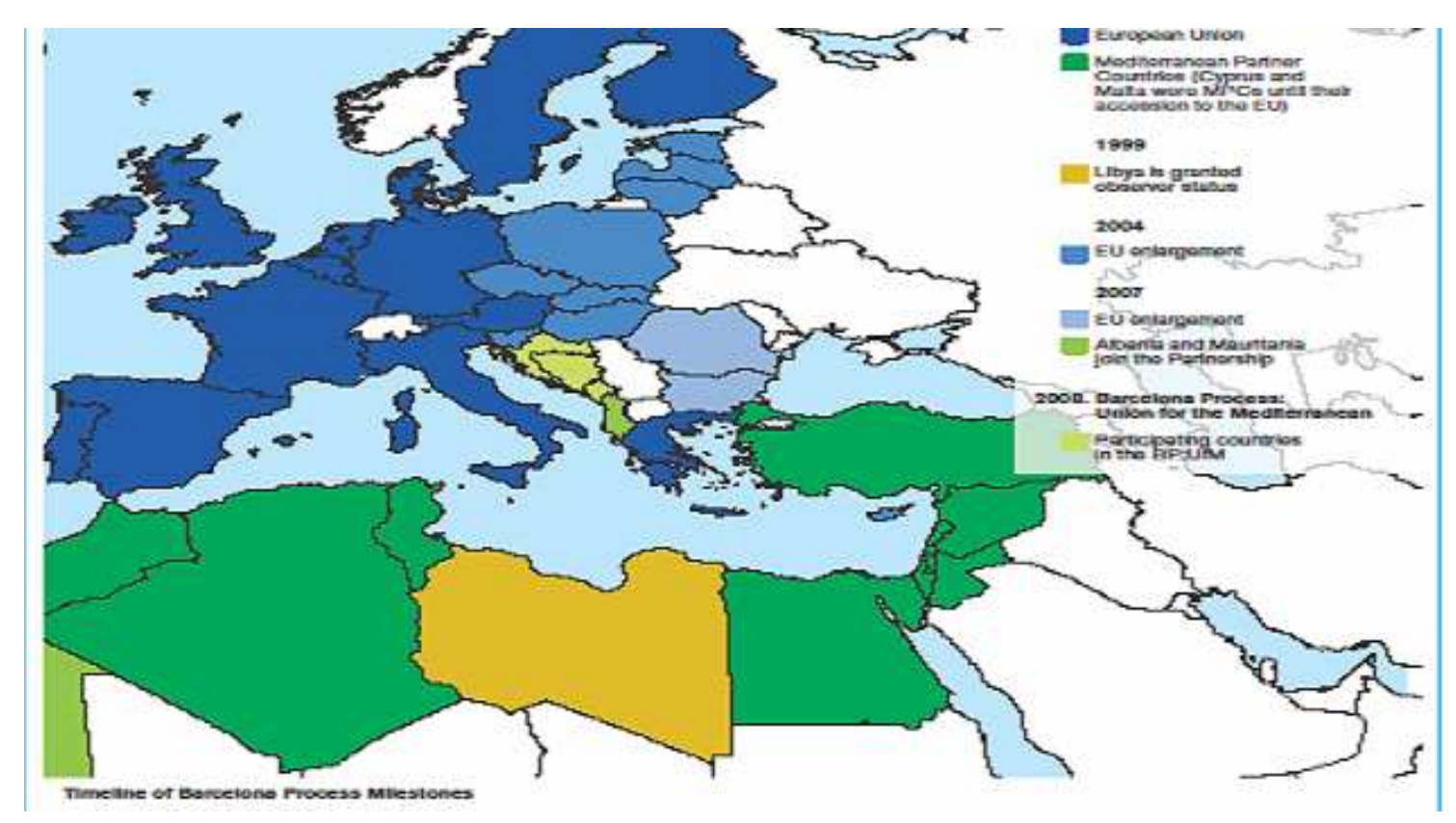

\footnotetext{
${ }^{4}$ Véase un amplio estudio sobre ampliación del espacio de seguridad mediterráneo en: Marquina Antonio (2011): “L'espansione dello Spazio di Sicurezza del Mediterraneo" en Mediterraneo:Porta di Oriente, Fondazione Roma-Mediterraneo, pp. 46-55.
} 
El diseño de este espacio creó desde el principio problemas con los socios del sur del Mediterráneo. Intelectuales árabes se quejaron de que dividía el espacio de la Liga Árabe en términos de seguridad ${ }^{5}$ (Véase Figura 2).

Figura 2. Espacio geográfico de la Liga Árabe

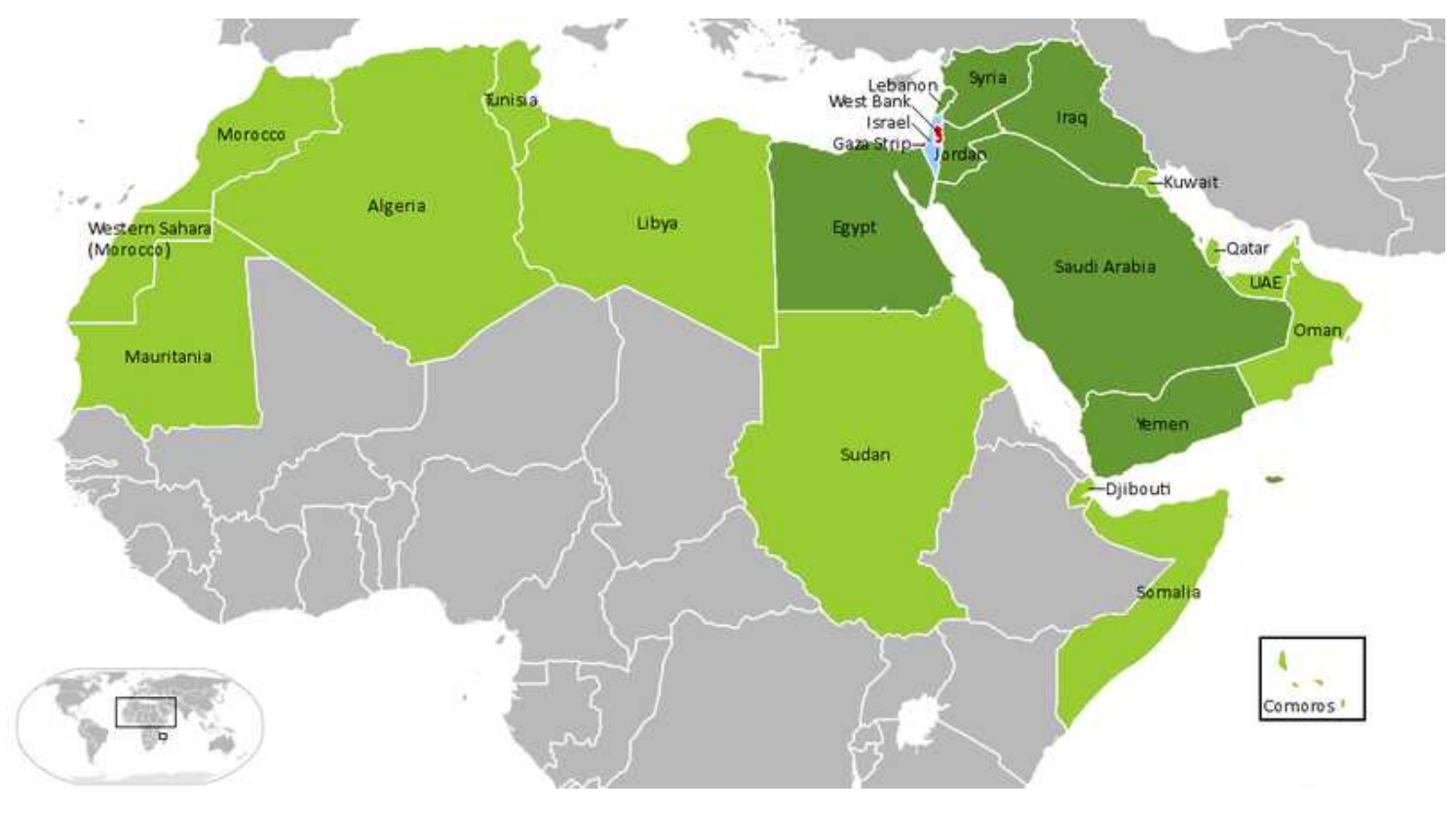

Una vez que se produjo la invasión de Irak por Estados Unidos en 2003, los socios de la Unión Europea en la zona del Mediterráneo Oriental empezaron a girar de forma resuelta hacia el Golfo Pérsico en términos de seguridad, en función de la situación creada en Irak tras la invasión y del diseño que realiza Estados Unidos en su intento de reconfigurar Oriente Medio, creando el Gran Oriente Medio. (Véase Figura 3)

\footnotetext{
${ }^{5}$ Marquina Antonio y Brauch Hans Günter (Ed) (2011): The Mediterranean Space and its Borders, Madrid UNSICI, cap.7.
} 
Figura 3. Mapa del Gran Oriente Medio (zona central o nuclear)

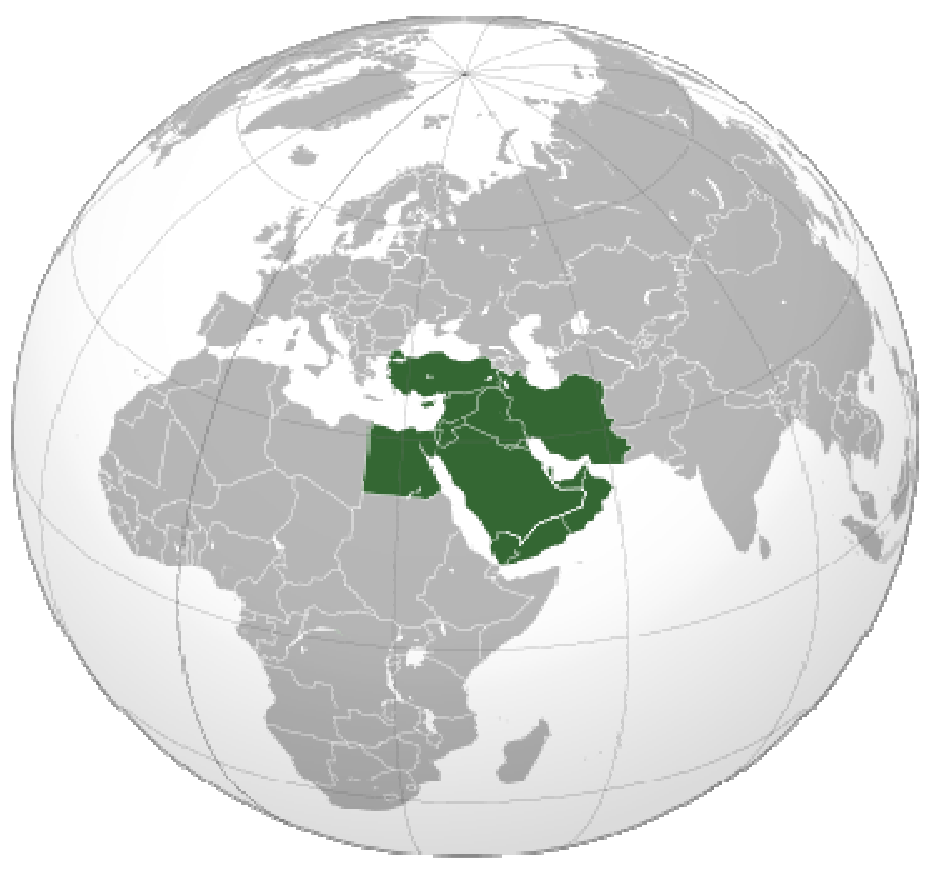

\subsection{El impacto de la invasión de Irak y las políticas de Irán en Oriente Medio}

La invasión de Estados Unidos de Irak va a suponer la quiebra del Estado iraquí con la ruptura y traumática transformación de los equilibrios políticos internos, induciendo una fuerte insurgencia y la fuerte penetración en influencia de Irán. Pasados unos años de creciente insurgencia y fuerte actividad de Al Qaeda, se iniciará una guerra civil con importantes implicaciones regionales. En 2006, tras el atentado de Samarra, se inicia la guerra abierta entre sunitas y chiitas, y los Estados Unidos buscan una salida para no ser cogidos como rehén en la guerra entre chiitas y sunitas. En los primeros meses de 2007, a pesar del incremento de 30.000 hombres que se estaban desplegando en Irak por Estados Unidos ("The Iraq surge"), cobra un nuevo impulso la idea de una "soft partition" de Irak creando 3 regiones semiautónomas, manteniendo un gobierno central y retirándose Estados Unidos a la periferia (véase Figura 4), idea que no acabó plasmándose gracias, sobre todo, al cambio de actitud de los líderes sunitas y la formación de "los hijos de Irak", así como, en menor medida, el cambio de actitud de líderes chiitas que trataron de limar las diferencias más salientes entre las dos comunidades. 
Figura 4. División de Irak

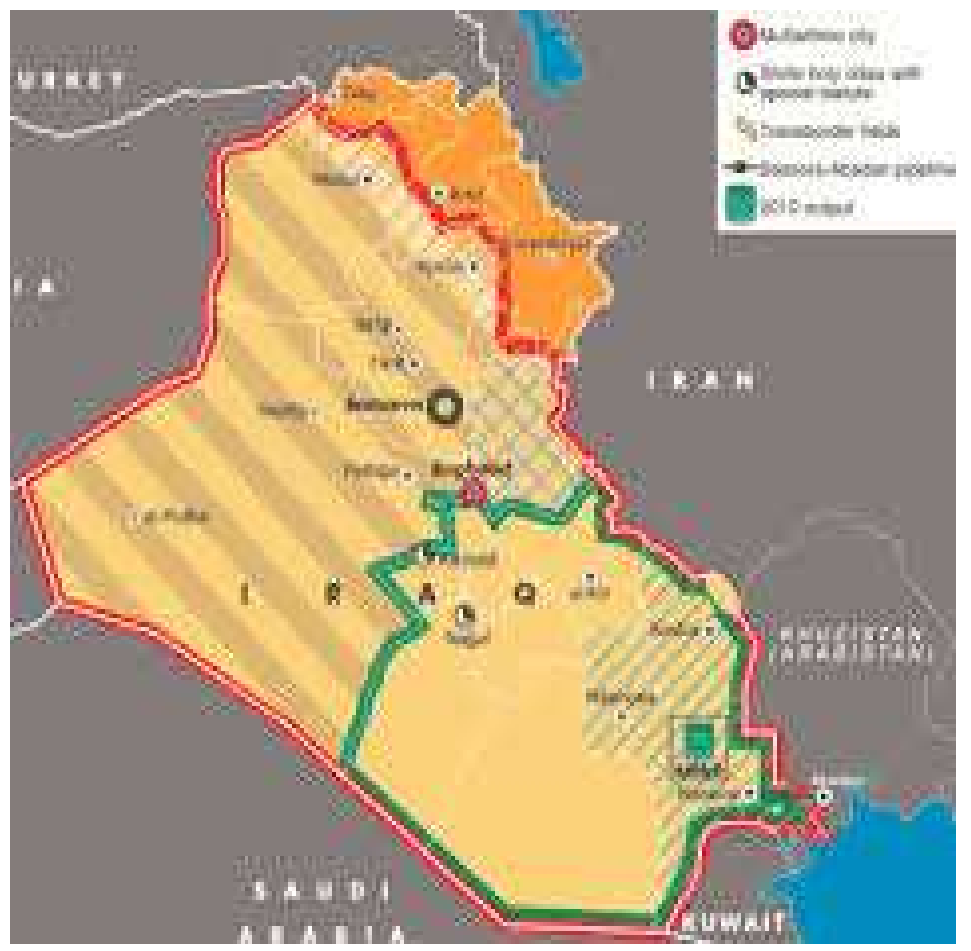

Aunque la situación mejoró a partir de agosto de 2007, la fragmentación y división entre las comunidades kurda, chiita y sunita permaneció. La retirada de las fuerzas de Estados Unidos el 31 de diciembre de 2011 no ha permitido un mejor entendimiento entre las tres comunidades y la situación de fragmentación y caos político todavía prevalece, a pesar de las elecciones realizadas, en medio de continuos atentados y claras tendencias independentistas en el Kurdistán iraquí.

Importante es resaltar también que esta ocupación va permitir a Irán ampliar su presencia en Oriente Medio en función de sus lazos con la mayoría chiita de Irak e inducirá un cierto alineamiento de políticas de los Estados sunitas vecinos con respecto a las políticas a desarrollar. Tanto Egipto como Siria, Jordania, Turquía e incluso, en buena parte, Israel, socios de la conferencia euro-mediterránea, centraron su atención en términos de seguridad en Irak y sus implicaciones regionales; el Mediterráneo en términos de seguridad se acabó ampliando, llegando al Golfo Pérsico.

Simultáneamente tendrá lugar la discusión sobre el programa nuclear iraní, reforzándose el giro de los socios de la Unión Europea en el Mediterráneo Oriental hacia el Golfo Pérsico, en función de las posibles consecuencias para su propia seguridad. La Unión Europea quedaba prácticamente marginada, a pesar de los diversos párrafos incluidos en el capítulo primero de la conferencia euro-mediterránea de Barcelona sobre no proliferación. El espacio de posible actuación sobrepasaba las capacidades de la Unión Europea, más aun teniendo en cuenta que el principal incentivo para un posible programa nuclear no meramente civil de Irán son las armas nucleares de Pakistán (Véase Figura 5). 
Figura 5. Espacio de interés en función del programa nuclear de Irán ${ }^{6}$

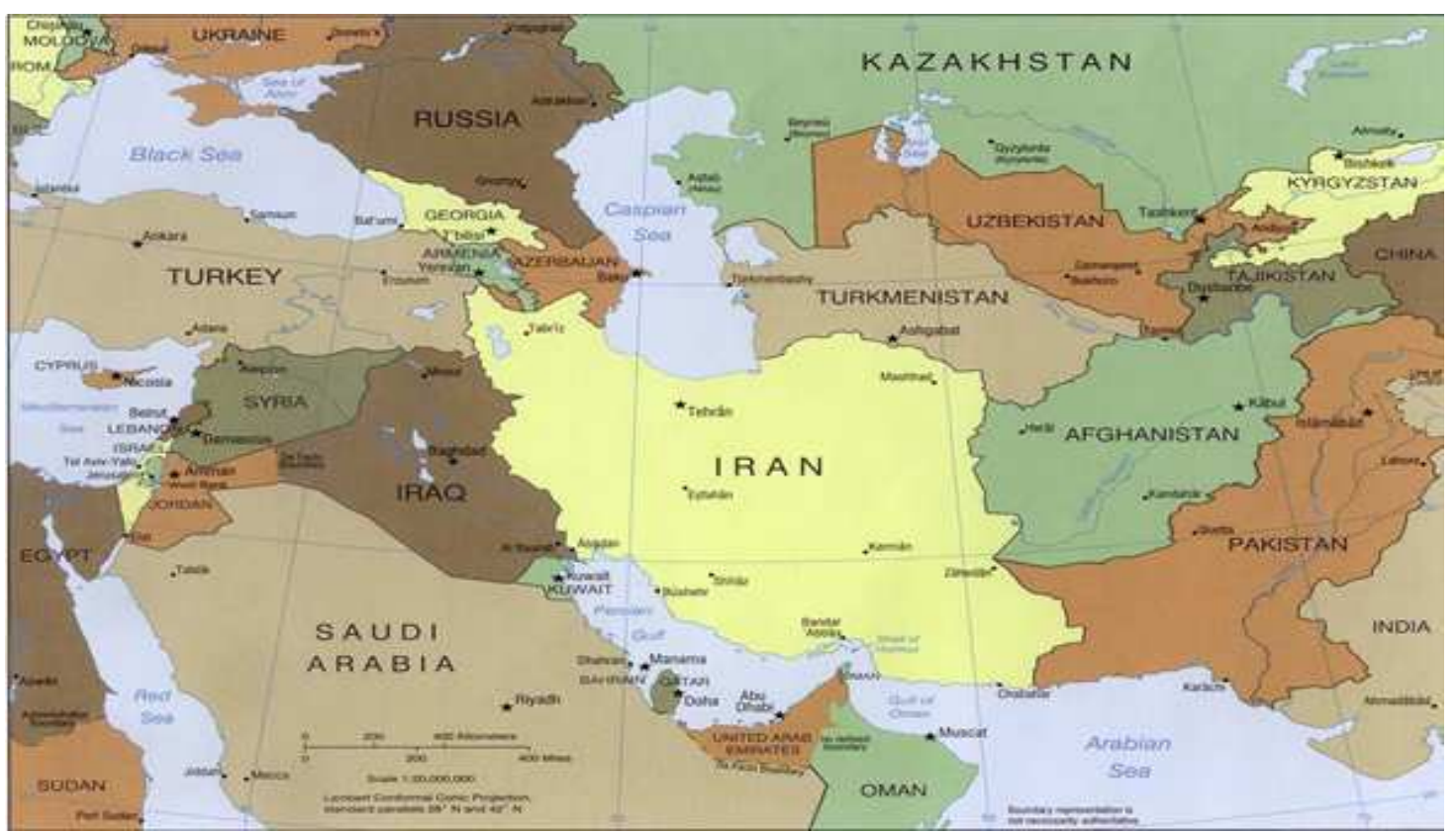

\subsection{La guerra civil de Siria y sus posibles implicaciones en el espacio de seguridad mediterráneo}

La ola de las revoluciones árabes alcanzó a Siria el 26 de enero de 2011, siendo el detonante la inmolación de un joven de 25 años que protestaba por el desempleo y las condiciones de vida existentes en su provincia de Al-Hasakah. Las protestas comienzan en núcleos de población periféricos, no en las grandes ciudades, pidiendo la reforma del sistema político, el fin de la corrupción, mejoras en el nivel de vida de la población y la finalización del estado de emergencia, son minoritarias. Pero a partir del 15 de marzo se va a producir una escalada en las manifestaciones demandando libertades políticas, el levantamiento de la ley de emergencia, liberación de todos los prisioneros políticos, el enjuiciamiento de las fuerzas de seguridad que han asesinado a manifestantes, y denunciando la corrupción.

A mediados de abril las revueltas se extienden y se hacen más violentas. A nivel interno el resultado es muy incierto para las fuerzas de oposición, capaces de movilizar a miles de personas, pero incapaces de establecer una plataforma unificada y un gobierno alternativo, dadas sus divisiones. A nivel internacional, la Liga Árabe apoya las reformas del gobierno sirio y no condena la actuación del gobierno, produciendo el estupor de los manifestantes y reduciendo las posibilidades de éxito de las fuerzas opositoras. No obstante, a mediados de 2011, desertores del Ejército comenzaron a organizar el Ejército Libre de Siria y, a finales de 2011, la guerra civil era ya una realidad que llega hasta nuestros días ${ }^{7}$.

\footnotetext{
${ }^{6}$ En este mapa aparece Pakistán, el principal incentivo para el posible desarrollo de un programa nuclear iraní que no fuese estrictamente diseñado para fines civiles. No obstante, la plasmación de un programa nuclear iraní, aunque sea el modelo japonés, tiene importantes repercusiones, afectando no solo a Turquía y los Estados del Golfo Pérsico, sino también a Egipto y otros países del norte de África.

7 Véase sobre este tema Marquina, Antonio (2011): "Los sucesos en el norte de África y Medio Oriente y sus implicancias en la seguridad mundial", en África y Medio Oriente: Una visión político estratégica, Santiago de Chile, Escuela de Guerra de Chile, Cuadernos de Difusión, pp.17-64.
} 
Los resultados de esta guerra civil de momento no están del todo claros, si bien ha ido ganando importantes posiciones el gobierno de Bashar al-Asad en el último año. Turquía, Jordania y los Estados del Consejo de Cooperación del Golfo han apoyado a las fuerzas opositoras, incluyendo los hermanos Musulmanes y fuerzas yihadistas ligadas a Al Qaeda, produciendo el retraimiento de los Estados occidentales. Mientras que el gobierno de Bashar al-Asad ha recibido importantes apoyos de Irán, Rusia, Hizbollah y grupos chiitas iraquíes.

A nuestros efectos es importante reseñar el papel de Turquía, en función de lo que después se señalará en este artículo y que viene recogido en la Estrategia de Seguridad Nacional 2013, que va a servir de base de entrenamiento y suministro a grupos yihadistas y servir de puente para la entrada y enrolamiento en la guerra de yihadistas europeos y de otras nacionalidades ${ }^{8}$.

En la actualidad podemos señalar una división territorial de facto existente en el país, con zonas de control de los diversos grupos combatientes claramente identificadas, destacando en el norte la zona controlada por los kurdos y la zona controlada por grupos rebeldes y yihadistas (Véase Figura 6)

Figura 6. Zonas de control, marzo de 2014

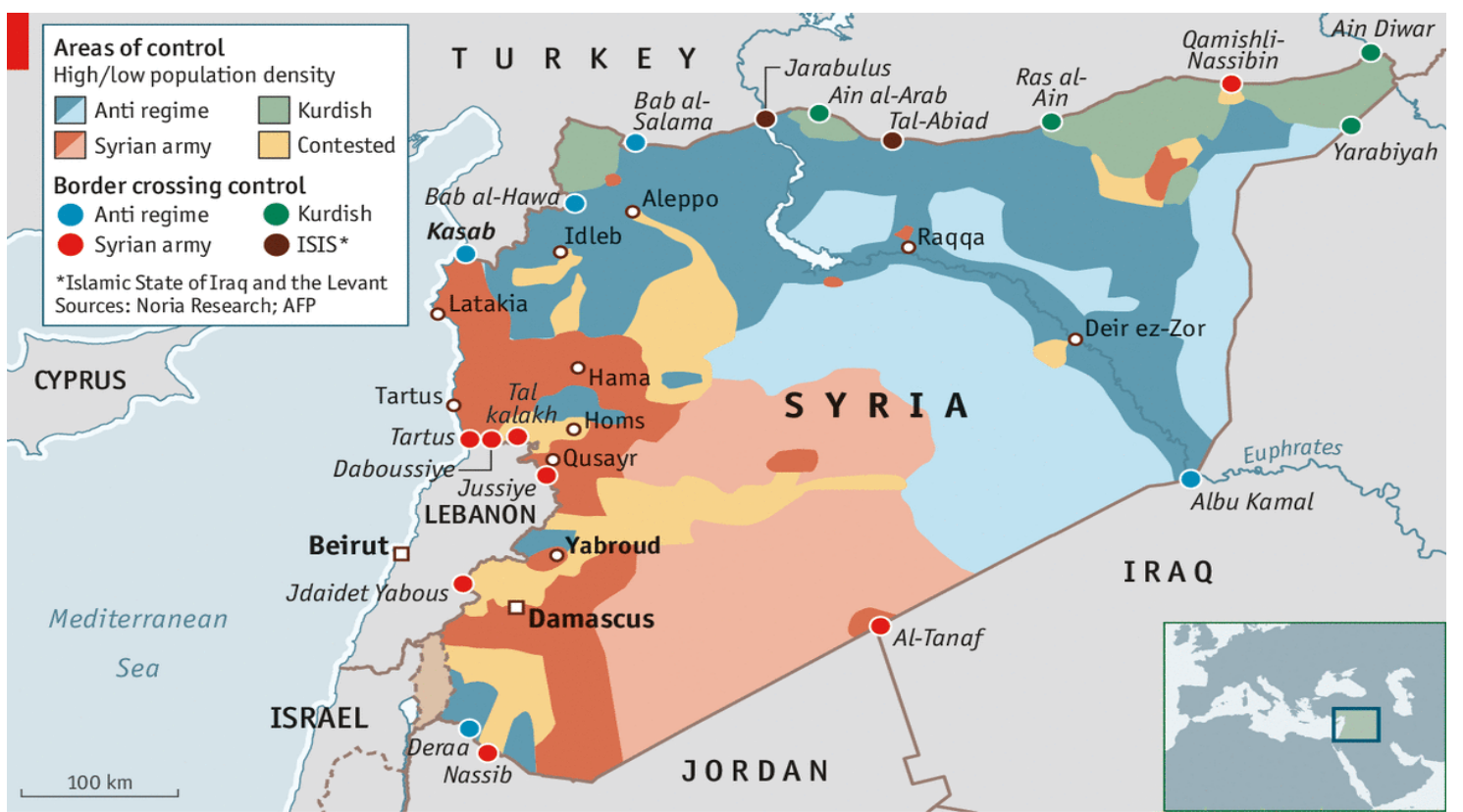

Si se acaban consolidando estas zonas de control, nos encontraremos con una importante zona controlada por grupos rebeldes y yihadistas sunitas, otra zona kurda que se apoya en el Kurdistán iraquí, una zona controlada por el gobierno de base alawita y una zona drusa en el sur de menor envergadura. El resultado puede ser un creciente impulso a la balcanización

\footnotetext{
${ }^{8}$ Véase entre diversos informes y artículos de prensa, Schanzer, Jonathan: "Terrorism Finance in Turkey: A Growing Concern", FDD PRESS, febrero 2014, en http://www.defenddemocracy.org/stuff/uploads/documents/Schanzer_Turkey_Final_Report_3_smaller.pdf.
} 
regional, afectando de forma especial a Siria, Turquía, Iraq y los Estados del Golfo Pérsico. Los siguientes mapas, con todas las limitaciones que se quieran poner, nos presentan un conjunto de posibilidades que podrían configurarse :

Figura 7. Configuración territorial posible de un Kurdistán independiente

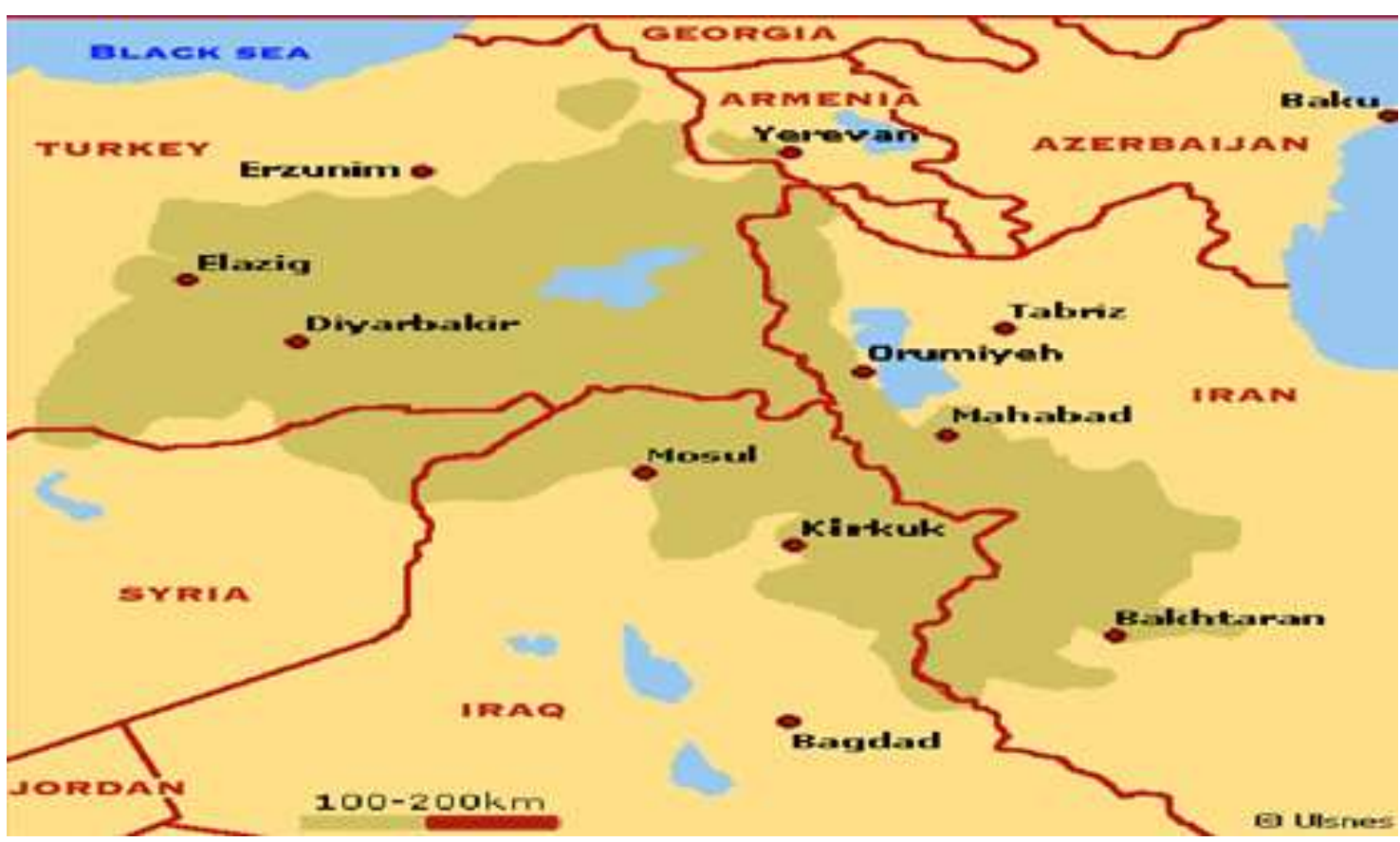

Figura 8. Impacto posible de la guerra en Siria en la reconfiguración de Siria e Iraq

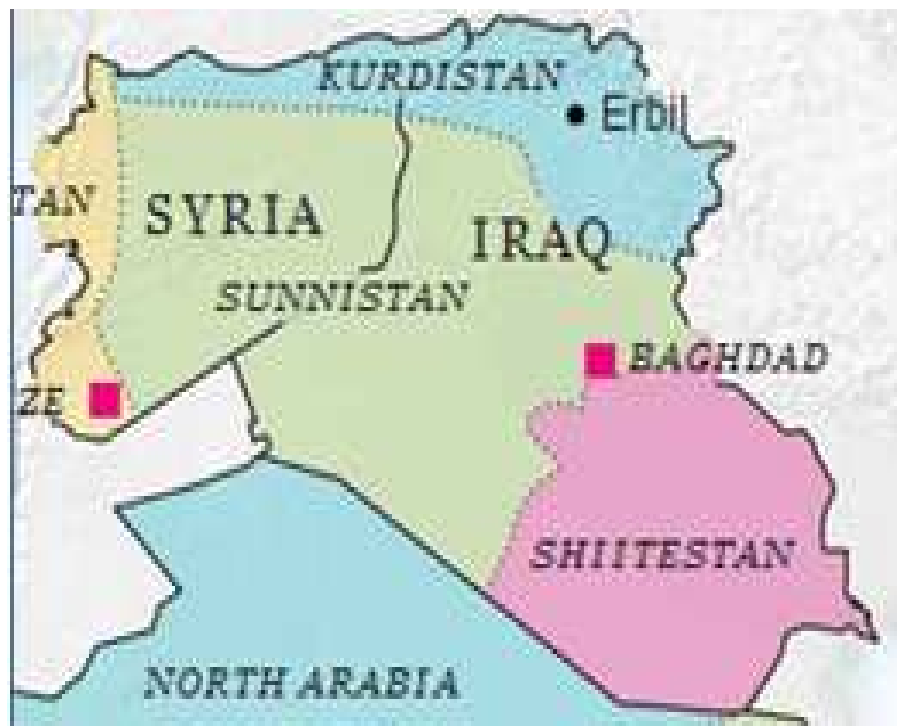

IRAN

Estas posibilidades llueven sobre mojado, tras lo ocurrido con la ocupación de Irak por Estados Unidos, induciendo la fragmentación de Irak y la creciente tendencia a la 
independencia del Kurdistán iraquí, y contribuyen a explicar la enorme preocupación de todos los Estados vecinos sobre las consecuencias para su seguridad del conflicto que se desarrolla en Siria, así como la preocupación de otros Estados mediterráneos que perciben las consecuencias para la seguridad del Mediterráneo en su conjunto, yendo más allá de planteamientos meramente geográficos.

\subsection{La guerra en Mali y la ampliación del tradicional espacio de seguridad mediterráneo al Sahel}

Asimsmo podemos señalar el impacto de la rebelión tuareg y la ocupación del norte de Mali. La muerte de Gadafi y la salida de Libia de grupos armados tuareg van a incidir de forma significativa en la región del Sahel. En enero de 2012 comenzó una nueva rebelión tuareg con una ofensiva del MNLA en el norte de Mali que en poco tiempo derrotó al ejército de Mali y le obligó a reitrarse hacia el sur. Luego se produjo el golpe de Estado militar en Bamako el 21-22 de marzo desalojando al gobierno por lo que considerban una desastrosa gestión del conflicto. La desorganización resultante permitió al MNLA y otros grupos armados conquistar las principales ciudades del norte y, así, el 5 de abril se declaró la independencia del Azawad, permitiendo una creciente presencia y penetración islamista y yihadista en esta zona ${ }^{9}$.

La situación creada en la zona, la falta de acuerdos y la preocupación de los paises vecinos y de Francia y otros paises europeos mediterráneos, todo ello indujo a que el Consejo de Seguridad aprobara las resoluciones 2071 y 2085 que permitían la intervención militar en Mali.

En enero de 2013, un vez que Ansar Din volvió a reanudar las hostilidades tomando la ciudad de Konna, amaneazando Sévaré, una localidad de gran importancia militar. El 10 de enero el presidente interino Dioncounda Traoré pidió ayuda militar a Francia y la ONU para frenar la rebelión y se produjo la intervención militar francesa con la operación Serval y rápidamente fueron conquistadas la principales ciudades del norte de Mali por las fuerzas francesas, el ejército de Mali y las fuerzas de los países africanos aliados ( Véase Figura 9).

\footnotetext{
${ }^{9}$ Véase, entre otros, Nievas David: "Rebelión y sharía en el Sahel: Una Aproximación al estallido de la rebelión Tuareg y la ocupación del norte de Mali pro grupos yihadistas e islamistas armados”, UNSICI Discussion Papers, $\mathrm{n}^{\circ} 34$ (Enero 2014), pp.119-138, en http://revistas.ucm.es/index.php/UNIS/article/viewFile/44836/42246.
} 
Figura 9. Intervención francesa con la Operación Serval

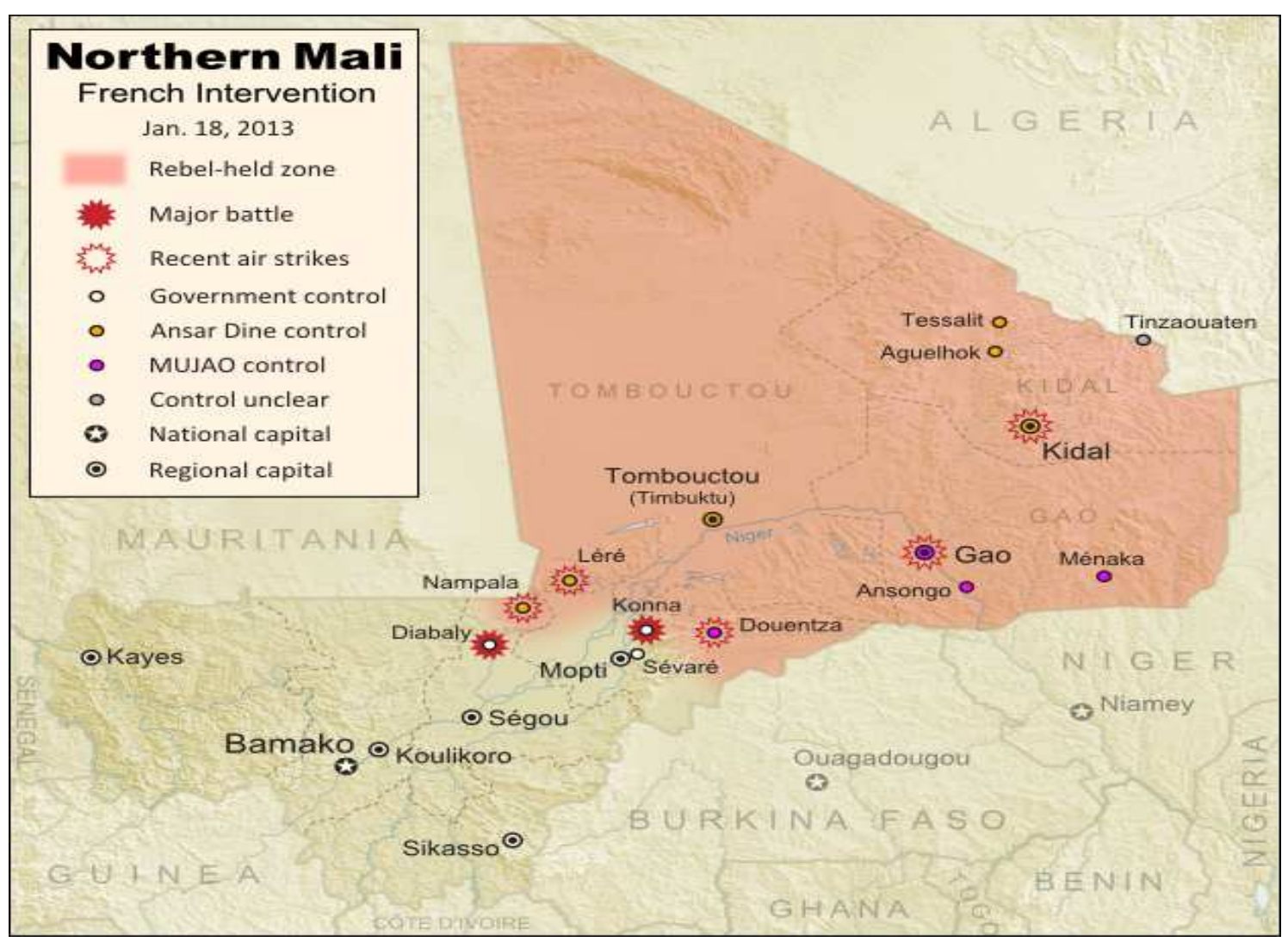

Esta operaciónes militares han contribuido a asentar en los paises de la Unión Europea, de forma especial en los países europeos del Mediterráneo occidental, la preocupación por la seguridad y estabilidad de la zona del Sahel. En muy poco tiempo se había pasado de considerar a Al Qaeda en el Magreb como un grupo de importancia secundaria, siendo Pakistán y Yemen el centro de atención tras la muerte de Bin Laden (2011), a un grupo de importancia capital, llegándose a no pocas exageraciones, como equiparar el norte de Mali con Afganistán, o considerar a grupos esencialmente mafiosos como grupos yihadistas de primer nivel $^{10}$, dejando de lado serias acusaciones de manipulación ${ }^{11}$. En cualquier caso, la intervención francesa y el lanzamiento de la operación de entrenamiento del ejército de Mali, EUTM Mali, con un mandato inicial de 15 meses, ha servido para cristalizar los planteamientos y posiciones que venían defendiendo la necesidad de ampliación del espacio

\footnotetext{
${ }^{10}$ Mesa Beatriz: "La transformación del yihadismo en el norte de Mali: De "causa" política a economía criminal”, UNISCI Discussion Papers, no 34 (Enero 2014), pp.103-118, en http://revistas.ucm.es/index.php/UNIS/article/viewFile/44835/42245.

${ }^{11}$ Véase por ejemplo, Garcon, José: "Les Gia sont une creatiom des services de sécurité Algeriens", Libération, 15 de noviembre del 2003; Schindler John R.: "The UglyTruth about Algeria", The National Interest, 10 de julio del 2012, en

http://nationalinterest.org/commentary/the-ugly-truth-about-algeria-7146 ; Keenan Jeremy: "How Washington helped Foster the Islamist uprising in Mali”, New Internationalist, diciembre de 2012, en

http://newint.org/features/2012/12/01; y también Keenan, Jeremy (2013): The Dying Sahara: US Imperialism and Terror in Africa, London, Pluto Press.
} 
de seguridad mediterráneo hacia la zona del Sahel, en función de la amenaza del terrorismo y el crimen organizado.

\section{Nuevos actores con presencia e influencia en el Mediterráneo: algunas consideraciones básicas a tener en cuenta}

Como con anterioridad indicamos, la Unión Europea, al lanzar la conferencia euromediterránea de Barcelona, partía de una posición de actor indiscutido que iba a tratar de enganchar a los socios mediterráneos en los procesos de globalización que se estaban desarrollando en el sistema internacional. Tenía medios económicos que ningún otro actor internacional estaba dispuesto a desembolsar o no podía entrar en competición con la Unión Europea, caso de Rusia tras la Guerra Fría. La situación actual ya no es la misma que la que existía en los años noventa. Rusia ha vuelto al Mediterráneo oriental con gran fuerza y la presencia de otros actores ha ido erosionando la capacidad de influencia indiscutida que tenía la Unión Europea en el Mediterráneo.A nuestros efectos nos ceñiremos a la presentación de dos actores principales. Rusia y China ${ }^{12}$.

\subsection{El incremento de la presencia e influencia de Rusia en el Mediterráneo}

Rusia tiene ya una presencia estratégica en la región y tiene fuertes intereses, dada la proximidad relativa del Mediterráneo Oriental a las fronteras de los Estados de la Comunidad de Estados independientes (CIS); teme la posible entrada de terroristas y fundamentalistas desde la región mediterránea al Caucaso norte; y está desarrollando importantes iniciativas de cooperación económica y comercial. De hecho, se puede decir que en 2010 Rusia ya había restaurado o establecido lazos políticos y económicos con todos los principales actores en la región: Iran, Siria,Arabia Saudita, Egipto, Catar, Iraq, Afganistán, Israel, Fatah, Hamas,Rusia ha sido siempre un actor con influencia en el conflicto árabe-ísraelí y palestino-israelíy Hezbollah. Estos lazos se vieron afectados por las revoluciones árabes que supusieron la destrucción o significaron una amenaza a buena parte de lo que habían conseguido, pero su actuación en la guerra civil en Siria y, más recientemente, el acercamiento a Egipto tras el derrocamiento del presidente Morsi,así como el incremento sustancial de la presencia naval en el Mediterráneo permiten aventurar un fuerte resurgimiento de la importancia e influencia de Rusia en el Mediterráneo.

La actuación diplomática y apoyos militares de Rusia al gobierno de Bashar al-Asad han significado poner un dique de contención a las pretensiones de Estados Unidos y de la Unión Europea de cambio de régimen. La Unión Europea, digno es de constatar, se ha mostrado completamente impotente para encauzar y solucionar este conflicto.

Desde el punto de vista militar, en 2012 Rusia incrementó su presencia naval en el Mediterráneo oriental y a partir de diciembre de 2012 ya va a realizar un despliegue permanente naval en el Mediterráneo.

\footnotetext{
${ }^{12}$ Un estudio que puede servir de referencia para la penetración de paises como Rusia, China, India y Brasil es Huber, Daniela; Bakhtin, Vladimir; Guofu, Li; Kumaraswamy, P.R. y Clemesha, Arlene: "The Mediterranean Region in a Multipolar World Evolving Relations with Russia, China, India, and Brazil", GMF (2013), en http://www.gmfus.org/wpcontent/blogs.dir/1/files_mf/1361299704BakhtinEtAl_MultipolarWorld_Feb13 web.pdf.
} 
Esta presencia se ha ido ampliando. El 6 de junio 2013 el jefe del estado mayor ruso anunció que Rusia iba a establecer una presencia naval permanente en el Mediterráneo con 16 barcos de guerra y 3 barcos portahelicópteros. Meses más tarde, el 13 septiembre de 2013, en plena crisis por el empleo de armas químicas en Siria, el almirante de la Flota, Viktor Chirkov, anunció que la marina rusa incrementaba su presencia en el Mediterráneo - de forma particular en la zona cercana a las costas de Siria- con 10 destructores.

Posteriormente, como consecuencia de la anexión de Crimea, Rusia anunció que 30 barcos, entre nuevos submarinos, barcos de superficie de nueva generación y barcos auxiliares se incorporarían a la Flota del Mar Negro, con un gasto estimado hasta 2020 de 2.430 millones de dólares ${ }^{13}$.

\subsection{La presencia creciente de China en el Mediterráneo}

China, de tener un presencia económica testimonial en el norte de Africa en los años noventa, cuando se lanza la iniciativa euro-mediterránea, ha llegado a ser una actor con una importante presencia política, social y económica. Su implantación creciente en esta zona difiere del modelo desarrollado para el Africa subsahariana.

Desde el punto de vista político el pais árabe mediterráneo central para China ha sido Egipto. En abril del 1999, China y Egipto acordaron mejorar y elevar sus relaciones bilaterales definiendo estas relaciones como estratégicas, siendo Egipto el primer Estado árabe que recibía este reconocimiento. Posteriormente en enero de 2004 por iniciativa de la Liga Arabe, se plasmó el Foro de Cooperación entre China y los Estados Arabes (CASCF) que ha facilitado la penetración económica y comercial China en el mundo árabe.

En el campo económico el interés inicial por los Estados árabes mediterráneos se centró en el gas y el petróleo de Argelia, Egipto y Libia, y también los fosfatos en Marruecos y Túnez, incrementándose muy notablemente las inversiones a partir de 2004, tras la formación del CASCF. También las infraestructuras de ferrocarril y carreteras y la construcción han sido un sector preferente, empresas chinas, por ejemplo, acabaron construyendo una parte importante de la autopista este-oeste de 1,216 km en Argelia o la conexión este-oeste por ferrocarril en Libia. En 2007 el monto de los contratos firmados por las empresas estatales chinas con Argelia llegó a ser el más importante de Africa y el quinto en el mundo ${ }^{14}$. Fuera de estos sectores, China ha invertido principalmente en el sector de electrónica, línea blanca, automoción y textiles. Como empresas importantes, fuera del sector gas/petróleo, se puede citar a Huawei, en Marruecos; Higer, Shaan Xi, Great Wall Computer Shenzhen Co. en Argelia; Hisense, Chinalco en Egipto. En Egipto se acabaron instalando 1.100 compañías y aproximadamente 35.000 chinos antes de la caída de Mubarak, quedando reducidos a unos 20.000 tras su dimisión. En Argelia, la cifra de chinos residentes llegó a alcanzar los 50.000. Por el contrario, la presencia de empresas chinas en Túnez ha sido tradicionalmente reducida, sólo cinco empresas chinas han venido operando en los últimos años.

\footnotetext{
${ }^{13}$ LaGrone, Sam: Russia to Expand Naval Presence in Black Sea as part of \$2.4 Billion Fleet Expansion, USNI NEWS, 6 de mayo del 2014, en http://news.usni.org/2014/05/06/russia-expand-naval-presence-black-sea-part-24-billion-fleet-expansion; "Russia's Black Sea Fleet to receive 30 new ships, become self-sufficient", $R T, 13$ de mayo del 2014 , en http://rt.com/news/158772-black-sea-fleet-ships/.

${ }_{14}$ Alden, Chris y Aggad-Clerx, Faten: "Chinese Investments and Employment Creation in Algeria and Egypt", $A f D B(2012)$, p.8, en

http://www.afdb.org/fileadmin/uploads/afdb/Documents/Publications/Brochure\%20China\%20Anglais.pdf.
} 
Al mismo tiempo, hay que señalar que las empresas chinas han hecho perder cuotas de mercado a las empresas del sur del Mediterráneo. Tanto en el sector textil, como el del calzado, como el del hierro y acero o la electrónica, las exportaciones chinas han quitado mercado a estos Estados, de forma especial en el mercado de la Unión Europea, y han contribuido a reconfigurar el mercado nacional desplazando a las empresas tradicionales. La caída del 22\% la producción en el sector textil en Marruecos a partir la finalización del sistema de cuotas de la Unión Europea en 2007, se debió a la agresividad comercial china.

Otro importante aspecto a señalar es la penetración china en el comercio de armamento. Egipto, en el período 1969-2008, se convirtió en el principal mercado en África para las empresas chinas de armamento ${ }^{15}$.

No obstante, el comienzo de las revoluciones árabes indujo pérdidas importantes en el comercio bilateral y para las compañías chinas. El comercio con Egipto se redujo. En Libia las 75 empresas chinas que operaban en el país sufrieron importantes pérdidas, habiendo de repatriar a 36.000 trabajadores chinos y sufriendo la destrucción de instalaciones y refinerías.

Las posibilidades de nuevos contratos en los Estados del norte de África se redujeron también, cayendo de forma muy significativa en el primer cuatrimestre de 2011, con respecto a lo realizado el año anterior. En Argelia, por ejemplo, un Estado donde el proceso revolucionario estuvo contenido, la reducción fue de un 70,8\%.

Ya en 2012 se asistirá a una recuperación de los intercambios comerciales. China tendrá dificultades iniciales en Libia al no haber apoyado desde el inicio a los grupos anti-Gadafi, pero China supo adaptarse a la nueva situación consiguiendo un primer gran contrato de suministro de petróleo (100.000 barriles de petróleo diarios) convirtiéndose en el tercer socio para las exportaciones libias y el primer socio en cuanto a importaciones.

En el caso de Egipto, los intercambios comerciales con China superaron a los intercambios con Estados Unidos ya en 2011. El nuevo presidente Morsi dejó bien claro que veía a China como un actor prioritario en sus relaciones bilaterales, al seleccionar a este Estado como el primero a visitar. En esta visita, realizada en agosto de 2012, China concedió a Egipto un préstamo de 200 millones de dólares y se firmaron diversos acuerdos en agricultura y en telecomunicaciones.

A su vez, el interés de China por Egipto venía sin duda dado por el bajo coste de la mano de obra y el número de acuerdos comerciales preferenciales que Egipto tenía firmados con la Unión Europea y con Estados de Africa y Oriente Medio, que le iban a permitir acceder a numerosos Estados, así como por poseer una vía de comunicación fundamental, el Canal de Suez.

China, en cualquier caso, se ha convertido en un socio clave de los socios europeos del sur del Mediterráneo. China es el segundo socio en las importaciones que realiza Egipto, el tercer socio en Argelia, el cuarto en Libia, el octavo en Túnez y el octavo en Marruecos, con claras perspectivas de mejora de posiciones. Si bien hay que recalcar que el déficit comercial de Egipto y Marruecos con respecto a China es amplísimo.

\footnotetext{
${ }^{15}$ Cunningham , Erin: "The United States Has A New Rival For Influence In Egypt", Business Insider, 6 de Septiembre del 2012, en http://www.businessinsider.com/mohammed-morsis-first-official-visit-is-to-china-2012-9.
} 
Junto a esta penetración económica hay que señalar la creciente presencia naval china en el Mediterráneo a partir de 2010. Los barcos chinos de la fuerza especial desplegada en el cuerno de Africa para la lucha contra la piratería han acabado haciéndose presentes en el Mediterráneo.Un destructor chino y una fragata llegaron a Egipto a finales de julio de 2010, realizando una visita de cinco días. Realizaron ejercicios con la marina italiana y visitaron el puerto de Taranto (OTAN), para después llegar al puerto de El Pireo en Grecia.

En agosto de 2012 un destructor y una fragata de China entraron en el Mediterráneo, atravesaron el Bósforo y visitaron Ucrania, Bulgaria y Rumanía, pero no hicieron ejercicios navales con Rusia y Siria como se esperaba.

Algunos analistas europeos y de Estados Unidos han empezado a preocuparse por esta presencia china, particularmente en Nápoles, donde existe un importante terminal naval de China que constituye un mirador con respecto a la principal base de la OTAN en el Mediterráneo.

En Grecia sin embargo, donde la inversión china es bastante popular. COSCO ha incrementado su tráfico en la terminal de contenedores de El Pireo, un $70 \%$ por año en los tres últimos años de operaciones.

En el año 2013 se puede reseñar la visita de una fragata china al puerto de Argel, el 2 de abril, permaneciendo cuatro días. El 9 de abril, la 13 fuerza naval de escolta, en misión de patrulla en el Golfo de Adén, llegó al puerto de Casablanca y el 5 de mayo, la 16 fuerza operativa de escolta llegaba a La Goleta, en Túnez, permaneciendo tres días.

Una nueva oportunidad para la presencia naval china en el Mediterráneo se presentó con motivo de loa necesidad de asegurar el transporte de las armas químicas de Siria. El 7 de enero de 2014, el crucero lanzamisiles ruso, Petr Velikly, y la fragata china,Yancheng, establecieron contactos para el apoyo en la seguridad del transporte de las armas químicas de Siria y el 25 de enero realizaron maniobras conjuntas consistentes en interacción operativa, aterrizaje de helicópteros, defensa antiaérea, disuasión de amenazas terroristas y rescate.

\subsection{El incremento de la influencia de los Estados del Consejo de Cooperación del Golfo}

La transferencia de rentas realizadas a nivel global a los Estados productores de gas y petróleo ha sido muy importante en la última década, al pasar el precio del barril Brent de petróleo de los 40 dólares en 2004 a los más de 100 dólares en la actualidad, habiendo alcanzado los 140 en 2008 y cotas superiores a 100 en 2011-2013.

El protagonismo de Estados como Catar quedó de manifiesto con el inicio de las revoluciones árabes, primero en Túnez y en Egipto, luego en Libia y Siria. Arabia Saudita ha constituido un importante apoyo en la lucha contra los Hermanos Musulmanes en Egipto, ha sostenido las monarquías de Marruecos y Jordania y ha intervenido financiando la oposición al regimen de Bashar al-Asad en Siria. El problema tradicional ha sido la rivalidad entre Estados árabes. Podemos citar la tensión entre el Egipto de Morsi y Arabia Saudita, luego el caso de Catar, así como el papel de Kuwait en la financiación de los rebeldes ligados a Al Qaeda que luchaban en Siria.

A pesar de las divisiones que han mantenido, es importante señalar el gran protagonismo económico y financiero de algunos de estos actores. Arabia Saudita prometió a diversos Estados Árabes, una vez iniciadas la revueltas, 17.900 millones de dólares: A Egipto 
4.000 millones, a Bahréin y Omán 5.000 millones, a Yemen 3.600 millones, a Jordania 2.650, a Túnez 750 millones, Marruecos 1.250 millones y a Palestina 340 millones. No obstante, en el informe anual del FMI sobre la economía saudí, publicado en septiembre de 2012, se afirmaba que la mayoría de estas cantidades no se habían hecho efectivas, en no pocos casos por no haberse implementado algunas políticas que convencieran a los donantes y prestamistas de que el dinero iba a ser gastado de forma eficiente, independientemente del impacto de la crisis económica. Un Estado como Catar, el 9 de mayo de 2013 acordó comprar bonos de Egipto a bajo interés por un monto de 3.000 millones de dólares que se añadieron a los 8.000 millones en ayudas al gobierno de los Hermanos Musulmanes realizadas en 20112012. Con respecto a Túnez, Catar, aparte de fuertes inversiones en diversos sectores, hizo un préstamo a bajo interés en 2012 de 1.000 millones de dólares y en 2013 depositó 500 millones de dólares en el Banco Central de Túnez para apoyar las reservas de moneda extranjera. En el caso de Egipto, tras el derrocamiento del presidente Morsi, el 9 de julio de 2013, Emiratos Árabes Unidos le prometió una donación de 1.000 millones de dólares y un préstamo de 2.000 millones de dólares, libre de impuestos. Al día siguiente, Arabia Saudita presentó un paquete de ayuda de 5.000 millones de dólares consistente en 2,000 millones como depósito en el Banco Central, 1.000 millones en dinero disponible y 2.000 millones de dólares en petróleo. Kuwait, a su vez, anunció que haría una aportación de 4.000 millones de dólares en dinero y en petróleo. Podemos comparar esta cifra de 12.000 millones no solo con el monto de las ayudas acordadas por la Unión Europea y las posibilidades de su condicionalidad, sino con la ayuda anual a Egipto por parte de Estados Unidos de 1.500 millones anuales que el Congreso de los Estados Unidos presionó para que fuera suspendida, una vez que se produce el derrocamiento del presidente Morsi. En el caso de Marruecos, Catar, Arabia Saudita, Kuwait y los Emiratos Árabes Unidos acordaron en 2012 una ayuda de 5.000 millones de dólares para el período 2012-2017. Una idéntica cantidad de 5.000 millones en cinco años se acordó también para Jordania ${ }^{16}$.

\section{Los planteamientos de la Estrategia de Seguridad Nacional 2013}

La Estrategia de Seguridad Nacional 2013 aborda el Mediterráneo considerandole como una zona prioritaria para la Seguridad Nacional y la del conjunto de Europa, y señalando los siguientes aspectos:

- La transformación del entorno estratégico, como consecuencia de las revoluciones árabes, donde la exclusión de grupos sociales o la utilización de la violencia violencia para obtener ventajas políticas pueden determinar un escenario altamente inestable con consecuencias muy negativas para los Estados de la ribera sur y la seguridad de toda la región..

- Un Mediterráneo estable, democrático y con mayores cotas de prosperidad es la mejor garantía de seguridad para todos los países de la región. Por lo que España

\footnotetext{
${ }^{16}$ Ver, entre otros: "Saudi aid to Arab Spring countries \$3.7 billion: IMF", Al Arabiya News, 19 de Septiembre del 2012, en http://english.alarabiya.net/articles/2012/09/19/239028.html; Sleiman, Mirna: "Analysis: Politics hinders aid to Arab Spring economies", Reuters, 27 de junio del 2012, en http://www.reuters.com/article/2012/06/27/us-mideast-aid-idUSBRE85Q0W720120627; Abi-Habib, Maria y Abdellatif, Reem: "Qatar's Aid to Egypt Raises Fears on Motives Gulf State Seeks Influence on Longtime Regional Power, Critics Says, With Loans to Muslim Brotherhood-Led Government", Wall Street Journal, 17 de mayo del 2013, en http://online.wsj.com/news/articles/SB10001424127887324031404578480771040838046; Schults, John: "Qatar signs aid deal worth \$1.25 billion for Morocco", Reuters, 28 de diciembre del 2013, en http://www.reuters.com/article/2013/12/28/us-morocco-qatar-aid-idUSBRE9BR06520131228.
} 
apoyará, junto a la UE y la comunidad internacional, los esfuerzos de los países de la zona para lograr un mayor desarrollo social y económico, además de una mayor estabilidad política.

- Repercusión en la seguridad del Sahel de la inestabilidad política y la ausencia de perspectivas económicas para gran parte de la población de estos países del Mediterráneoe y que pueden afectar a España y Europa.

- Interés particular del Magreb para España. Por lo que España, en colaboración con los Estados de la zona, debe dar respuesta a retos comunes para ambas orillas consistentes en :

- el impulso al Estado de Derecho,

- el desarrollo económico y la cohesión social,

- la consolidación de modelos económicos que favorezcan la inclusión de todos los ciudadanos,

- la estabilización de los suministros energéticos,

- la regulación y el control de los flujos migratorios,

- la lucha contra el terrorismo, el narcotráfico y demás tráficos ilícitos internacionales.

En este contexto, el documento señala que:

- España debe fomentar la seguridad común en el Mediterráneo no únicamente de forma bilateral, sino también a través del impulso y liderazgo de marcos más amplios de cooperación, como la Unión por el Mediterráneo, la Política Europea de Vecindad y otros foros como, por ejemplo, la "Iniciativa 5+5", el Diálogo Mediterráneo de la OTAN o la Iniciativa de Cooperación de Estambul de 2004.

Posteriormente se centra en los conflictos, destacando que

- existen conflictos antiguos y muy complejos que afectan a la seguridad de todos y el impacto de guerras recientes en Libia y Siria, para señalar dos conflictos, el israelopalestino y el del Sahara Occidental.

- En el primero España había de seguir trabajando en el marco de la Unión Europea para un arreglo definitivo del conflicto israelo-palestino según los parámetros acordados.

○ Y en el segundo, España ha de matener un compromiso activo en su solución, de conformidad con las resoluciones de Naciones Unidas.

Finalmente se destaca:

- el problema de Chipre donde España contribuirá a una solución justa y definitiva

- la colaboración con Turquía como actor regional relevante para la seguridad y la estabilidad del Mediterráneo Oriental. 
Si comparamos esta Estrategia con la Estrategia Española de Seguridad de 2011 encontramos algunas diferencias. No se citan en 2013 las ciudades de Ceuta y Melilla que sí se citaban en 2011. Tampoco se citan las Islas Canarias siendo así que en 2011 se citaban en el contexto del Mediterráneo Oriental que se ponía al mismo nivel de prioridad que el Magreb. Además, en 2011 se citaba a Irán y los esfuerzos que España tenía que hacer junto con la Unión Europea y la ONU para integrarlo en la comunidad internacional.

En todo lo demás se podía decir que había continuidad, salvo en la cuestión de Chipre y el seguidismo de la política de Turquía que no se mencionaban en 2011. El énfasis en el papel de España en la solución del conflicto israelo-palestino era mayor en 2011, al calificar a España como uno de los actores más activos en el diálogo y la búsqueda de soluciones.

Si comparamos la Estrategia de Seguridad Nacional 2013 con el Libro Blanco de Francia podemos ver alguna similitud en el planteamiento del Magreb como zona prioritaria, aunque se enfatice en el Mediterráneo el desafío potencial que pueden suponer los vacíos de seguridad en ciertos Estados o en ciertas zonas para el conjunto del Mediterráneo y el sur de Europa $^{17}$.

\subsection{Las deficiencias de la Estrategia de Seguridad Nacional 2013}

La cuestión es evaluar hasta qué punto la Estrategia se adecua a la realidad de los actuales desafíos de seguridad existentes en el Mediterráneo en su evaluación, diseño y actuaciones que se contemplan.

La primera sorpresa es la falta de adecuación de los planteamientos a la realidad del espacio de seguridad mediterráneo y sus posibles consecuencias regionales, para España y para la Unión Europea. Porque, si bien el vecindario más próximo manda, léase el Magreb, e incluso la inclusión del Sahel no es desacertada, el impacto de una desestabilización en Oriente Medio sea vía una profunda inestabilidad o reconfiguración de Siria o Irak, o los avances en la creación de un Estado independiente kurdo tendrían efectos devastadores en la estabilidad y seguridad regional, afectando a todos los Estados de la región incluyendo Turquía, tal como hemos tratado de presentar en el apartado 2 de este artículo. Incluso la ausencia de una solución creíble al programa nuclear de Irán tendrá unos efectos devastadores no solo para Oriente Medio sino para todo el Mediterráneo y otras zonas regionales. Y, en este sentido, la Estrategia Española de Seguridad de 2011 no estaba descaminada. Otra cuestión que aquí no vamos a desarrollar es si el Tratado de no-proliferación resulta ya viable como marco de estabilidad, dada su falta de universalidad, el no cumplimiento de todos los compromisos asumidos con motivo de su extensión indefinida, o las violaciones sistemáticas en no pocos casos del espíritu y la letra de varios de sus artículos, en especial los artículos 3, 4 y 6.

El segundo aspecto a señalar es un cierto parroquialismo trasnochado. La Estrategia de Seguridad Nacional 2013 y la Estrategia Española de Seguridad de 2011 vienen a considerar implícitamente que las diversas iniciativas europeas o de la OTAN para el Mediterráneo siguen siendo la base fundamental de sustentación para la solución o encauzamiento de los problemas de seguridad y estabilidad mediterráneos, donde incluso, se cree que España puede tratar de liderar ${ }^{18}$ como en los años 1994-1995. La ceguera es colosal. El apartado 3 de este

\footnotetext{
17 "Livre Blanc. Défense et Securité Nationale-2013", Direction de l'information légale et administrative, Paris, (2013), p.54.

${ }^{18}$ Esto no significa que se minusvalore lo que la Unión Europea hace y pueda hacer. Lo que se pretende es redimensionar ilusiones inerciales. En efecto, la Unión Europea en 2012 ha desarrollado diversos tipos de
} 
artículo ha tratado de mostrar someramente la importancia e influencia creciente en el Mediterráneo de otros actores no europeos que incluso en términos económicos han contribuido a ridiculizar las aportaciones europeas y las condicionalidades europeas a la hora de afrontar las revoluciones árabes. ¿Cómo es posible que este aspecto tan importante, que contribuye a condicionar de forma radical toda la Estrategia, no se haya tenido en absoluto en cuenta? ¿Ha servido para algo el diálogo mediterráneo de la OTAN a la hora de afrontar las revoluciones árabes? El diálogo mediterráneo de la OTAN, confrontado con las revoluciones árabes, ha contribuido mínimamente a la seguridad y estabilidad regional, a pesar de ser uno de sus objetivos. La iniciativa de cooperación de Estambul no merecería ni haberse nombrado. $i$ Es que, por ejemplo, en 2013 no se estaba viendo lo que estaba ocurriendo en Siria y la impotencia de la Unión Europea frente a la actividad de otros actores no europeos?

En tercer lugar la prioridad del Magreb. Si bien esta prioridad es indiscutible, dada sus cercanía y los desafíos que tiene que afrontar esta zona regional, Los retos comunes que se presentan para el Magreb son unos retos poco imaginativos y claramente deficientes. Están hechos mirando al retrovisor. Hay que incluir la nueva agenda de seguridad, yendo más allá de los felices noventa, que contiene retos comunes básicos de importancia capital, como el impacto a corto y medio plazo del cambio climático, de los desafíos de seguridad alimentaria $^{19}$, de los desafíos que supone el necesario cambio de la utilización masiva de combustibles fósiles hacia energías renovables ${ }^{20}$. Estos son temas de enorme complejidad y que están llegando o están ya con nosotros, y que hay que afrontar cuanto antes mejor.

En cuarto lugar existe un fallo en la Estrategia de Seguridad Nacional 2013 que no deja de sorprender y es el apoyo y colaboración con las políticas de Turquía (la colaboración con Turquía como actor regional relevante para la seguridad y la estabilidad del Mediterráneo Oriental), dejando de lado el conflicto de Chipre que supera de forma evidente las capacidades y las posibilidades de España. Está claro que Turquía es un Estado con el que España ha de tener óptimas relaciones, pero esta pretensión de colaboración con Turquía en Oriente Medio es un error de principiante o de chico de escuela. Así se ha acabado demostrando. Turquía, intentando defender sus intereses nacionales, ha ido variando el diseño inicial de sus políticas para Oriente Medio- Golfo Pérsico ${ }^{21}$. Acabó rompiendo con Israel, adoptó una posición muy nacional en el conflicto de Libia y también acabó dejando de lado la política estrella de "cero problemas con los vecinos". Incluso ha incluido actuaciones en Siria, como mencionamos con anterioridad en el artículo, que implican un doble juego muy peligroso. Todo esto era ya claro y meridiano en 2013.

reuniones con organizaciones regionales como la Liga Árabe, adoptándose un programa conjunto de trabajo y ha apoyado la cooperación regional con el Magreb, centrada en cuatro áreas prioritarias, según lo acordado en la reunión de 27 de septiembre de 2013 con los ministros de Asuntos Exteriores de los Estados del Magreb: 1.Diálogo político y cooperación de seguridad, 2.-Agricultura, Medioambiente y Agua 3.-Industria, infraestructura, comercio, inversiones y tecnología, incluyendo energía, turismo, información y comunicaciones, 4.-Desarrollo humano.

19 Ver por ejemplo: Marquina, Antonio (2013): Una devastación incipiente. La seguridad alimentaria en el Magreb, Madrid, Foro Hispano-Argelino, UNISCI, 485 p.

${ }^{20}$ En el último borrador del IPCC enviado a los gobiernos en diciembre de 2013, se dice que, de manera a poder mantener un crecimiento de la temperatura por debajo de $\operatorname{los} 2^{\circ} \mathrm{C}$ a nivel global en este siglo, las inversiones en combustibles fósiles deberían disminuir en 30.000 millones de dólares al año y las inversiones en energías renovables deberían incrementarse en 147.000 millones de dólares anuales.

${ }^{21}$ Véase Marquina, Antonio y Aydin, Mustafa (2006): Turkish Foreign and Security Policy. Its Environs in Eurasia and the Middle East, Madrid, UNISCI, 303 pp.; Aydin, Mustafa (2010): Turkish Foreign Policy. Old Problems, New Parameters, Madrid, UNISCI, 333 pp. 
La quinta sorpresa aparece al mencionar y tratar dos conflictos: el israelo-palestino y el conflicto del Sahara Occidental. En el primer caso, las pretensiones españolas han partido de una lectura bastante equivocada de la posición del primer ministro Netanyahu sobre el proceso de paz, en el que no cree, a lo que se añade una visión de las posibilidades de la Unión Europea que están más que sobredimensionadas. Una cosa es la política y otra la gesticulación. La Unión Europea ni es admitida como actor en la negociación por Israel, ni presenta un frente suficientemente unido que le permita presentarse como un actor respetable y respetado en cualquier proceso negociador.

La mención al Sahara occidental y el compromiso activo español, a la vista de lo ocurrido desde 2004 con las políticas de España ${ }^{22}$, es algo que hubiera convenido, quizás, pasar por alto.

La sexta sorpresa es que no aparezcan citadas Ceuta y Melilla y tampoco Gibraltar, que aparece citado no esta sección, sino en la sección dedicada a la Unión Europea.

La cuestión del estrecho de Gibraltar no es un asunto baladí y mucho menos su banalización en una estrategia de seguridad. Ceuta y Melilla y Gibraltar aparecen, no obstante, citados, si bien con poca profundidad, en la Estrategia de Seguridad Marítima Nacional de 2013. Este es un asunto que no queda bien encuadrado en la Unión Europea al implicar su defensa continuada un desgaste grande para España con unos posibles resultados bastante relativos. La cuestión es que la colonia de Gibraltar limita muy seriamente el despliegue español y es un contencioso sobre el que se ha vertido bastante desinformación que incluso llegó a cristalizar en altos mandos españoles ${ }^{23}$. Si bien es cierto que es un asunto que implica ya al territorio circunvecino español más de lo que hubiera sido deseable, no es menos cierto que ello ha sido debido también a la pasividad, la incuria y la incompetencia española ${ }^{24}$. Ha de engarzarse claramente con los planteamientos de seguridad española en el Mediterráneo, mucho más en la actualidad en función de los cambios acelerados que se están produciendo en el sistema internacional, lo que exige una atención continuada, pues, además, siempre se ha jugado con el cansancio español.

\section{Conclusión}

La conclusión es breve y constituye una llamada de atención. La Estrategia de Seguridad Nacional 2013 en lo que respecta al Mediterráneo se ha hecho de forma muy deficiente y mirando por el retrovisor, sin percatarse de las implicaciones que conllevan varios asuntos que son cardinales: la ampliación hacia Oriente Medio- Golfo Pérsico del espacio de seguridad mediterráneo; la presencia e influencia creciente en los asuntos mediterráneos, incluidos los de seguridad, de otros actores no europeos, que compiten y tienden a relativizar sustancialmente la tradicional importancia y papel de la Unión Europea en el Mediterráneo; el creciente extrañamiento sur-norte, donde la importancia del factor religioso se ha devaluado y

\footnotetext{
${ }^{22}$ Ver: Marquina, Antonio (2012) "La política exterior de España hacia el Mediterráneo en la última década. Una evaluación”, en Marquina, Antonio: Crisis, Inercias y Agotamiento: Repensando la Política Exterior Española, Madrid, UNISCI.

${ }^{23}$ Marquina, Antonio: "La política sobre Gibraltar del nuevo Gobierno español”, UNISCI Discussion Papers, $\mathrm{n}^{\circ}$ 29 (Mayo de 2012), p.228, en http://revistas.ucm.es/index.php/UNIS/article/viewFile/40670/38992.

${ }^{24}$ Este sería el momento de hacer una evaluación de lo acontecido en este contencioso desde la muerte del general Franco: las políticas mantenidas, los giros de 180 grados y hasta los abusos realizados contra quienes se atrevieron a discrepar con las políticas/ausencia de política que se estaban desarrollando. La historia juzgará el patriotismo de cada cual.
} 
minusvalorado, extrañamiento que relativiza en buena parte iniciativas como el diálogo mediterráneo de la OTAN y otros diálogos mediterráneos; la importancia de nuevos desafíos para la seguridad común; y la importancia continuada del estrecho de Gibraltar. Todos estos asuntos constituyen y constituirán muy serios desafíos que España tendrá que encarar. Y cuanto antes lo haga, de forma bilateral y multilateral, será mejor para todos. 